\title{
Role of hypoxia-induced exosomes in tumor biology
}

\author{
Chuchu Shao ${ }^{1,2 \dagger}$, Fengming Yang ${ }^{2 \dagger}$, Suyu Miao ${ }^{3 \dagger}$, Weitao Liu ${ }^{4}$, Chaoshan Wang ${ }^{4}$, Yongqian Shu ${ }^{1,2^{*}}$ \\ and Hua Shen ${ }^{1,2^{*}}$
}

\begin{abstract}
Purpose: Hypoxia is a major regulator of angiogenesis and always influences the release of exosomes in various types of tumors. The present review aimed to assess the role of hypoxia-induced exosomes in the tumor biology.

Methods: The relevant publications were retrieved from PubMed using keywords such as hypoxia, exosome, extracellular vesicles, tumor, cancer, and other similar terms.

Results: Recent studies have shown that cancer cells produce more exosomes under hypoxic conditions than do parental cells under normoxic conditions. The secretion and function of exosomes could be influenced by hypoxia in various types of cancer. Hypoxia-induced exosomes play critical roles in tumor angiogenesis, invasion, metastasis, and the immune system.
\end{abstract}

Conclusions: These findings provide new insights into the complex networks underlying cellular and genomic regulation in response to hypoxia and might provide novel and specific targets for future therapies.

Keywords: Exosome, Extracellular vesicles, Hypoxia, Cancer

\section{Background}

Hypoxia, the condition of insufficient oxygen, is a common feature of malignant tumors. In a majority of malignancies, the median oxygen level is about $10 \mathrm{mmHg}$, while the normal tissues have rather high oxygen pressure (between 40 and $60 \mathrm{mmHg}$ ) [1]. This phenomenon is attributed to the high oxygen demand from proliferating cancer cells and low oxygen supply due to irregularities in tumor vascularization or distance from supporting blood vessels [2, 3]. Hypoxia has been well acknowledged as an intricate element of the tumor microenvironment involved in tumor aggressiveness and metastasis [4-6]. In response to hypoxia, the cancer cells alter the transcription of numerous genes in conjunction with the oxygen-monitoring mechanism, including hypoxia-inducible factors (HIFs), the major components of hypoxia signaling pathways [7].

HIFs are dimeric proteins that comprise of an oxygen-sensitive subunit HIF- $\alpha$ (HIF- $1 \alpha$, HIF- $2 \alpha$, or HIF- $3 \alpha$ ) and a constitutively expressed HIF-1 $\beta$ subunit $[8,9]$. In

\footnotetext{
* Correspondence: shuyongqian1998@163.com; medshenhua@126.com ${ }^{+}$Chuchu Shao, Fengming Yang and Suyu Miao contributed equally to this work ${ }^{1}$ Department of Oncology, The Affiliated Sir Run Run Hospital of Nanjing Medical University, Nanjing, China

Full list of author information is available at the end of the article
}

the presence of oxygen, HIF- $1 \alpha$ is hydroxylated by prolylhydroxylase (PHD), following which, the hydroxylated HIF- $1 \alpha$ is recognized by von Hippel-Lindau (VHL). This serves as the targeting subunit of an E3 ubiquitin ligase complex and thereby tags HIF-1 $\alpha$ for ubiquitination and degradation by the $26 S$ proteasome [10]. However, under hypoxic conditions, PHDs are no longer active to hydroxylate HIF- $1 \alpha$, resulting in HIF- $1 \alpha$ stabilization and dimerization with HIF- $1 \beta$. The expression of HIF- $1 \alpha$ is also influenced by another oxygen sensor factor-inhibiting HIF-1 $\alpha$ (FIH). As a key regulator of HIF- $1 \alpha$, FIH-1 catalyzes an asparagine hydroxylation step that controls the association of HIF- $1 \alpha$ transcription factors with $\mathrm{CBP} / \mathrm{p} 300$ transcriptional co-activators and reduces the transcriptional activity of HIF-1 $\alpha$ [11]. Given the observations that most malignant tumors experience hypoxic conditions, HIFs activation occurs in almost all types of cancer. A large part of HIF-dependent hypoxic response relies on intercellular signalling, which regulates the expression of genes associated with angiogenesis, epithelial-to-mesenchymal transition (EMT), metastasis to promote cell survival and the adaptation of cells to 
hypoxic conditions [12]. In addition to intercellular hypoxic signaling pathways, recent studies have shown the importance of the crosstalk between tumor cells and their microenvironmental factors via extracellular vesicles (EVs)s secreted from hypoxic tumor cells [13].

EVs are cell-derived vesicles with different sizes and intracellular origins, which can be characterized into three categories: exosomes (30-100 $\mathrm{nm}$ diameter), microvesicles (MVs) (100-1000 nm diameter), and larger vesicles termed oncosomes (1-10 $\mu \mathrm{m}$ diameter) [14-17]. Recently, the role of EVs, especially exosomes secreted by tumor cells in modulating cell-to-cell communication has been highlighted [18, 19]. Exosomes are generated from the inward budding of late endosomes, and thus, released into the extracellular space upon fusion with the plasma membrane $[20,21]$. Once released into the extracellular space, exosomes can reach the recipient cells and deliver the contents to elicit the functional responses and promote phenotypic changes that would affect the physiological or pathological status [22]. The contents of exosomes are complex, including various types of proteins, RNAs, and DNAs that can act as messengers for cell communication in local and distant microenvironments [23-25]. RNAs are reported as the major bioactive factors of tumor cell-derived exosomes, along with several species of non-coding RNAs including microRNAs (miRNAs), long non-coding RNAs (lncRNAs), and circular RNAs [26-28]. These functional non-coding RNAs delivered by exosomes to recipient cells can regulate numerous gene expression to promote tumor growth, local invasion, and create premetastatic or metastatic niches.

It is now clearly evident that exosomes derived from tumor cells play critical roles in modulating the tumor microenvironment [13]. Recent findings have reported that hypoxia stimulate increased levels of exosomes, thereby facilitating tumor intercellular communication at a distance, indicating a role of exosomes as vital regulators in hypoxic tumors $[29,30]$. In breast cancer, the cancer cells exposed to hypoxia has been reported increase their production of exosomes in an HIF-dependent manner, which stimulate invasion and metastasis by contacting with recipient cancer cells [31]. In the present review, we will discuss how exosomes induced by hypoxia participate in tumor angiogenesis, invasion, metastasis, and immune system.

\section{Hypoxia induces the release of exosomes}

Exosomes are vital mediators of intercellular communication that can transfer the cells' phenotype to non-hypoxic cells through the production of exosomes. As mentioned above, recent researches indicated that hypoxia can induce the release of exosomes. Target genes include numerous plasma membrane receptors such as glucose transporter (GLUT-1), epidermal growth factor receptor
(EGFR), transfer receptors, P-glycoprotein (P-gp), and multidrug resistance protein 1 (MRP1). The altered receptor expression can increase the receptor activation and internalization or result in receptor clustering, which consequently induces endocytosis and promotes exosome release [32]. Interestingly, the small GTPases, RAB27A and RAB27B, were implicated in exosome secretion in human HeLa cells [33, 34]. In breast cancer, RAB22A was also required for mediating the formation of extracellular vesicles [31]. However, the specific molecular mechanisms regulating the exosome secretion are yet to be elucidated.

In addition to the quantitative impact of exosome secretion, hypoxia stress also causes significant changes in the content and function of exosomes. As Kore et al. found that hypoxic exosomes derived from GBM cells selectively elevated some proteins such as protein-lysine 6-oxidase (LOX), thrombospondin-1 (TSP1) and vascular derived endothelial factor (VEGF), which were known to be associated with tumor progression, metastasis and angiogenesis [35]. Moreover, several pieces of evidence have established that hypoxia regulates the expression of different non-coding RNAs delivered by exosomes. For example, miR-210 is a well-established target of HIF- $1 \alpha$ and strongly induced in most cancer types in response to hypoxia. King et al. demonstrated that breast cancer cells release high levels of exosomes and miR-210 in hypoxic exosomes in an HIF-1 $\alpha$-dependent manner. Furthermore, three different breast cancer cell lines were exposed to moderate $\left(1 \% \mathrm{O}_{2}\right)$ and severe $\left(0.1 \% \mathrm{O}_{2}\right)$ hypoxia, leading to significant increase in the number of exosomes [36]. Similarly, in another study addressing the molecular mechanisms regulating exosomal shedding, Umezu et al. found that hypoxia-resistant multiple myeloma (HR-MM) cells produced more exosomes with a significantly higher expression of miR-135b as compared to normoxic cells, indicating that the tumor-secreted exosomes could be induced by hypoxia [37].

\section{Hypoxia influence the exosomes secreted by the tumor microenvironment}

Most tumors develop a hostile tumor microenvironment associated with the expansion of hypoxic and necrotic areas as the existing vasculature cannot fulfill the increasing oxygen demand of rapidly expanding tumors. The tumor microenvironment can be subdivided into the chemical microenvironment (for example, low oxygen, low $\mathrm{pH}$, and low nutrition), the diverse extracellular signaling molecules, and the cellular microenvironment, which include tumor cells, stromal cells, extracellular matrix (ECM), and inflammatory immune cells [38]. The immune component of the tumor microenvironment is comprised of myeloid cells including tumor-associated macrophages (TAMs), myeloid-derived suppressor cells (MDSCs), dendritic cells (DCs), and tumor-infiltrating lymphoid cells (TILs). All these cells are greatly affected 
by hypoxic stress present in the tumor microenvironment. Hypoxia can interfere with the differentiation and function of immune cells by modulating the expression of co-stimulatory receptors and the type of cytokines produced by these cells. Furthermore, exosomes secreted by other cells also could be influenced by hypoxia. For example, Fernanda et al. revealed that the TGF- $\beta 1$-containing exosomes from injured epithelial cells activate the fibroblasts that in turn, initiate tissue regenerative responses and fibrosis. Thus, the present study suggested that TGF- $\beta 1$ mRNA transported by exosomes constitute a rapid response initiating the tissue repair/regenerative responses and the activation of fibroblasts when resident parenchyma is injured [39].

The content of hypoxia-induced exosomes varies depending on the cell origin including signal transducers, transcription factors, enzyme, lipids, mRNAs, and non-coding RNAs. In different cancers, exosome-mediated signaling promotes tumor progression through communication between the tumor and surrounding stromal tissues, involving tumor angiogenesis, invasion, metastasis, and immune escape. The function of exosome-mediated signaling pathways under hypoxic states will be discussed in the following sections.

\section{Hypoxia-induced exosomes enhance cancer angiogenesis} Angiogenesis is a complex process involving the sprouting and configuring of new MVs from pre-existing blood vessels $[40,41]$. It is a critical step in cancer progression via stimulation of the tumor growth. This process is highly regulated by a group of ligands and receptors through multiple signaling pathways. The proangiogenic signaling molecule vascular endothelial growth factor (VEGF) and its cognate receptor (VEGFR) play a central role in angiogenesis and are highly expressed in tumor tissues [42]. VEGF signaling stimulates cellular pathways that lead to the formation and branching of new tumor blood vessels, facilitating rapid tumor growth, and metastatic potential [43]. The development of antiangiogenic treatments by several investigators is focused on inhibiting the VEGF/VEGFR signaling.

Recent studies have highlighted the role of hypoxia-induced exosomes in angiogenesis and tumor development. For example, exosomal miR-135b has also been found to be transferred into endothelial cells by hypoxia-resistant multiple myeloma (HR-MM) cells and target HIF-1, thereby enhancing angiogenesis [37]. Exosomes isolated from hypoxic lung cancer cells contained miR-23a, which increased the angiogenesis by targeting prolyl hydroxylase and tight junction protein $\mathrm{ZO}-1$ [44]. Also, Tadokoro et al. reported that exosomes derived from hypoxic leukemia cells enhanced the tube formation in human umbilical vein endothelial cells (HUVECs) via miR-210 [45]. Moreover, Mao et al. revealed that hypoxia- induced miR-494 promotes angiogenesis in non-small cell lung cancer (NSCLC). Firstly, hypoxia induces the expression of miR-494 via the HIF-1 $\alpha$-mediated mechanism. The upregulated miR-494 was secreted from tumor cells into microenvironment and delivered into ECs via exosomes, followed by downregulation of PTEN and activated Akt/eNOS pathway in ECs; consequently, the tumor development is exacerbated by promoting angiogenesis [46] (Fig. 1).

\section{Hypoxia-induced exosomes promote cancer cell invasion and metastasis}

Invasion and metastasis are the determination features of malignant tumors. It is well-known that tumor invasion and metastasis involve multiple steps, among which, the epithelial-mesenchymal transition (EMT) is an absolute and crucial step for metastasis [32]. During EMT, the cancer cells shed their epithelial features, remodel their cytoskeleton, and acquire a mesenchymal phenotype that correlates to enhanced migratory and invasive capacity [47]. At the molecular level, the changes occurring during EMT are explained by the loss of epithelial and the gain of mesenchymal markers. The loss or downregulation of E-cadherin is a major event in EMT, and it can be identified as one of EMT biomarkers [48]. It is known as a transmembrane glycoprotein expressed in epithelial cells that regulate cell-to-cell contact, cell shape, and polarity [49]. Moreover, it connects the adjacent cells through homophilic interactions as well as linked to the cytoskeleton via a multi-catenin complex that is attached to their cytoplasmic tails $[50,51]$. In this complex, $\beta$-catenin and p120 are directly associated with E-cadherin, while $\alpha$-catenin is the link between $\beta$-catenin and the actin microfilament network of the cytoskeleton [52]. Loss of E-cadherin results in the loss of cell-to-cell contact, disruption of E-cadherin-catenin complex, abnormal activation of $\beta$-catenin signaling, and cellular cytoskeletal alterations. Overall, these changes are essential for the cells to lose their epithelial polarity and acquire an invasive phenotype [53].

An increasing number of studies provide novel evidence that under hypoxic conditions, the migration and invasion ability of cancer cells can be enhanced by hypoxia-induced exosomes. Ramteke et al. reported that hypoxia-induced exosomes promoted the invasiveness and metastasis of prostate cancer cells by targeting adherens junction molecules [54]. In the study, hypoxia-induced exosomes promoted the loss of E-cadherin in PC3 cells along with an increase in cytoplasmic and nuclear $\beta$-catenin expression, which might be responsible for the observed increase in the invasiveness, motility, and stemness of PCA cells by TDEs. Consecutively, another study also found that hypoxia enhances the exosome-mediated shuttling of lncRNA-UCA1 into bladder cancer cells, and hypoxic exosomal lncRNA-UCA1 also promotes 


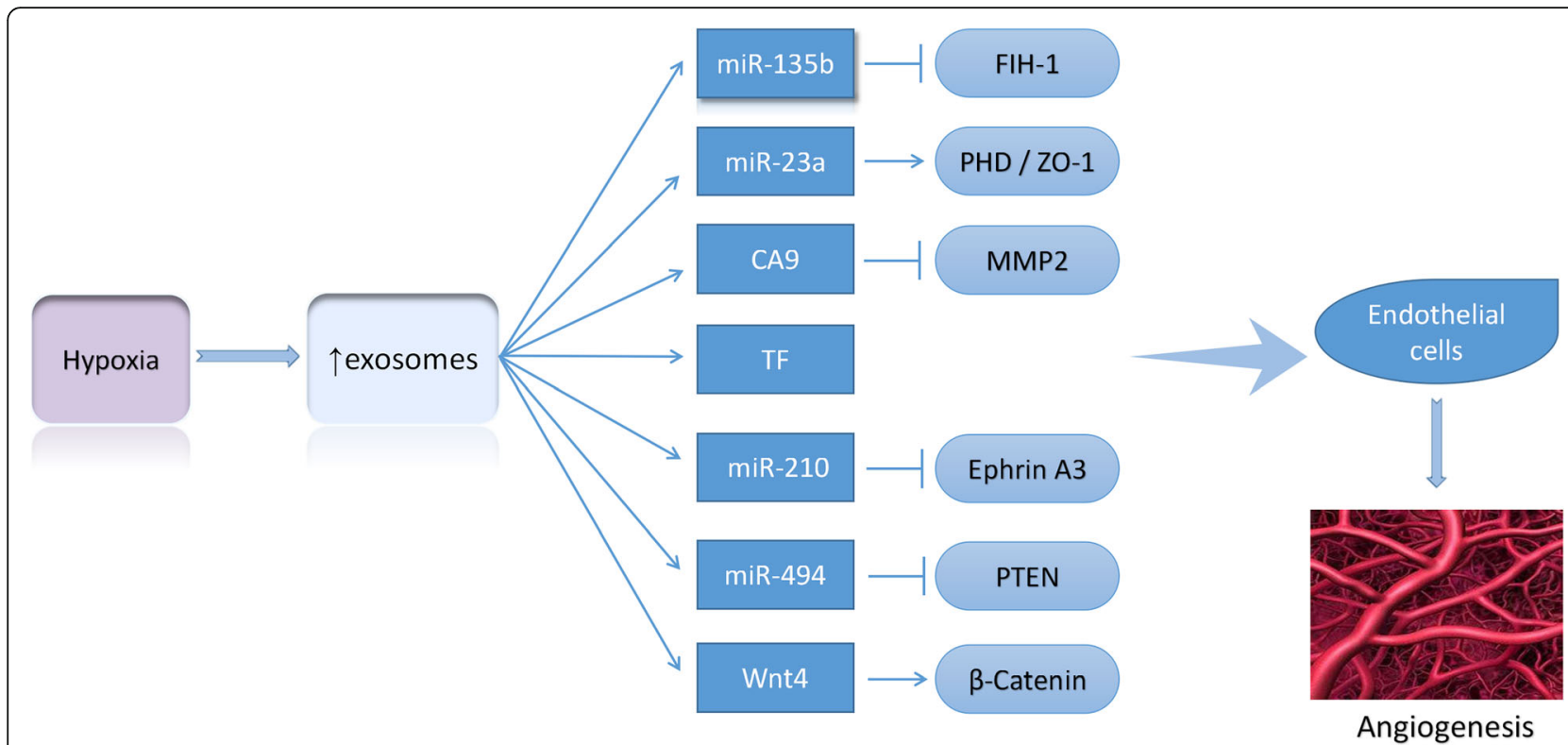

Fig. 1 Hypoxic-induced exosomes promote angiogenesis in multiple cancers. Under chronic hypoxic conditions, cancer cells secrete higher levels of exosomes. The upregulated exosomal ncRNAs and specific proteins induced by hypoxia are taken up by the surrounding endothelial cells, resulting in the accelerated angiogenesis

development, invasion, and migration of tumor cells in vitro and in vivo [55]. Furthermore, Ling et al. showed that exosomes from oral squamous cell carcinoma (OSCC) cells were upregulated under hypoxia, and the upregulated exosomal miR-21 downregulates a pool of genes and induces EMT of the target normoxic cells [56]. Other studies provide more evidence on the role of hypoxic-induced exosomes in tumor invasion and metastasis as below (Table 1).

\section{Hypoxia-induced exosomes influence cancer immune system}

Reduced immune surveillance is a key mechanism through which primary tumors create permissive environments in secondary organs that favor the development of metastasis [57-59]. Accumulating evidence has shown that tumor-derived exosomes induce T-cell apoptosis, reduce NK cells activity, inhibit IFN- $\gamma$ dependent class II expression of macrophages, and alter the differentiation of monocytes to increase the myeloid-derived suppressor cell (MSDCs) population, which leads to a collective failure of the immune system in containing the cancer growth [60-64]. For example, SW et al. found that breast cancer exosomes directly suppress the T-cell proliferation and inhibit the NK cell cytotoxicity, and hence suppressed the anticancer immune response in premetastatic organs [65]. MiRNAs in lung cancer cell-derived exosomes can silence the transcripts associated with Toll-like receptor (TLR) family in macrophages. This mechanism stimulates the macrophages to secrete proinflammatory cytokines, which supports enhanced tumor dissemination. Cancer cells are capable of inhibiting the anti-tumor functions of the host immune system via an exosome-induced signaling mechanism [66]. Moreover, $\mathrm{T}$ lymphocytes are not the sole immune cells targeted by tumor-derived exosomes. The activities of human NK cells, B-cells, and monocytes are impaired by co-incubation in the presence of exosomes. In NK cells, the downregulation of the expression of the activating receptors, especially NKG2D, is induced by tumor-derived exosomes carrying the MICA and MICB ligands [67]. NK-cell activation and cytotoxicity are inhibited by TGF- $\beta$, which is predominantly displayed on exosomes as TGF-latency associated protein (TGF-LAP). Moreover, tumor-derived exosomes can synthesize adenosine from ATP by virtue of carrying CD39 and CD73, which are implicated in inducing suppressive activity in activated B cells as adenosine can convert the activated B-cells into regulatory B-cells [68]. In addition, tumor-derived exosomes skewed the differentiation of myeloid precursor cells towards development into highly suppressive MDSCs [69].

Interestingly, a recent study found that hypoxia induces macrophage polarization involving the expression of exosomes in epithelial ovarian cancer [70]. In addition, the study demonstrated that SKOv3 cells under hypoxia expressed much more miR-940 than the cells under normoxia, as well as, in exosomes. Moreover, hypoxic exosomes induced macrophages to express higher levels of the M2-type markers, CD163 and CD206, as compared to normoxic exosomes. These data suggested that exosomes could deliver miR-940 to macrophages and that hypoxic exosomes could induce macrophages to an M2-like phenotype. Also, Berchem demonstrated that 
Table 1 Hypoxia-induced exosomes involved in cancer biology

\begin{tabular}{|c|c|c|c|c|c|}
\hline Regulatory factors & Cancer types & Response to hypoxia & Biological function & Mechanism & Ref \\
\hline Exosomal miR-135b & Multiple myeloma & Increased & Increase angiogenesis & Downregulates its target $\mathrm{FIH}-1$ & [37] \\
\hline Exosomal miR-23a & Lung cancer & Increased & $\begin{array}{l}\text { Increase angiogenesis } \\
\text { and migration }\end{array}$ & Inhibition of PHD1, PHD2 and ZO-1 & [44] \\
\hline Exosomal miR-210 & Leukemia & Increased & Increase angiogenesis & Inhibits the expression of Ephrin A3 & [45] \\
\hline Exosomal miR-494 & Non-small cell lung cancer & Increased & Increase angiogenesis & $\begin{array}{l}\text { Downregulates PTEN and activates } \\
\text { Akt/eNOS pathway in ECs }\end{array}$ & [46] \\
\hline Exosomal miR-21 & Oral squamous cell carcinoma & Increased & $\begin{array}{l}\text { Promote migration } \\
\text { and invasion }\end{array}$ & $\begin{array}{l}\text { Downregulate a pool of genes and } \\
\text { induces EMT of these cells. }\end{array}$ & [56] \\
\hline Exosomal miR-940 & Epithelial ovarian cancer & Increased & $\begin{array}{l}\text { Regulate immune } \\
\text { response }\end{array}$ & $\begin{array}{l}\text { Induces macrophages to express } \\
\text { higher levels of the M2-type } \\
\text { markers CD163 and CD206 }\end{array}$ & [70] \\
\hline Exosomal miR24-3p & Nasopharyngeal carcinoma & Increased & $\begin{array}{l}\text { Regulate immune } \\
\text { response }\end{array}$ & Not mentioned & [71] \\
\hline Exosomal miR-210 & Hypoxic cancer & Increased & Increase angiogenesis & $\begin{array}{l}\text { Inhibits the expression of Ephrin } \\
\text { A3 and PTP1B }\end{array}$ & [72] \\
\hline Exosomal linc-UCA1 & Bladder cancer & Increased & $\begin{array}{l}\text { Promote migration and } \\
\text { invasion }\end{array}$ & Promotes EMT & [55] \\
\hline Exosomal linc-RoR & Hepatocellular cancer & Increased & $\begin{array}{l}\text { Promote migration and } \\
\text { invasion }\end{array}$ & Not mentioned & [73] \\
\hline Exosomal proteins & Prostate cancer & Increased & $\begin{array}{l}\text { Promote migration and } \\
\text { invasion }\end{array}$ & Not mentioned & [54] \\
\hline Exosomal CA9 & Renal cell carcinoma & Increased & Increase angiogenesis & Upregulates its target MMP2 & [74] \\
\hline Exosomal TF & Glioblastoma multiforme & Increased & Increase angiogenesis & $\begin{array}{l}\text { Enhances TF/NIla-mediated PAR-2 } \\
\text { activation and activates endothelial } \\
\text { cells }\end{array}$ & [75] \\
\hline Exosomal Wnt4 & Colorectal cancer & Increased & Increase angiogenesis & $\begin{array}{l}\text { Increases } \beta \text {-catenin nuclear } \\
\text { translocation in endothelial cells }\end{array}$ & [76] \\
\hline Exosomal MMP13 & Nasopharyngeal carcinoma & Increased & $\begin{array}{l}\text { Promote migration and } \\
\text { invasion }\end{array}$ & Not mentioned & [77] \\
\hline Exosomal HIF1a & Nasopharyngeal carcinoma & Increased & $\begin{array}{l}\text { Promote migration and } \\
\text { invasion }\end{array}$ & Promotes EMT & [78] \\
\hline $\begin{array}{l}\text { Exosomal TGF- } \beta 1 \\
\text { and miR23a }\end{array}$ & Hypoxic cancer & Increased & $\begin{array}{l}\text { Regulate immune } \\
\text { response }\end{array}$ & $\begin{array}{l}\text { TGF- } \beta 1 \text { downregulates NKG2D and } \\
\text { miR23a directly targets CD107a }\end{array}$ & [79] \\
\hline
\end{tabular}

hypoxic tumor-derived MVs (TD-MVs) negatively regulate the NK cell function by a mechanism involving TGF- $\beta 1$ and miR23a transfer. The hypoxic TD-MVs transfer TGF- $\beta 1$ to NK cells, decreasing the cell surface expression of the activating receptor NKG2D, thereby inhibiting the NK cell function. Subsequently, miR-23a in hypoxic TD-MVs serve as an additional immunosuppressive factor as it directly targets the expression of CD107a in NK cells. Moreover, exosomal miR-24-3p is enriched in hypoxic cells from nasopharyngeal carcinoma (NPC) cells. The present study showed that NPC tumor-derived exosomes inhibit T-cell proliferation and Th1 and Th17 differentiation, while inducing the differentiation of regulatory T-cells (Tregs) [71] (Fig. 2).

In conclusion, exosomes act as biologically active vesicles that exert a negative impact on the functions of different types of immune cells by mechanisms engaging more than one molecular pathway responsible for the genetic changes in recipient cells.

\section{Future perspectives}

According to the studies mentioned above, hypoxiainduced exosome-mediated cellular communication is a key signaling mechanism involved in numerous pathological problems. A major mechanism of exosome-mediated cell-to-cell communication is speculated to exert protection of the encapsulated components from degradation, thereby allowing the transfer of exosomal cargo to distant recipient cells. This phenomenon suggests that the biological effects of exosomes are exerted following cellular entry and cargo release. However, the contribution of initial signaling activation upon attachment of exosomes to recipient cells with respect to the functional effects of the subsequent cargo transfer remains unclear. Despite extensive research on the role of specific cargo delivery for exosome-mediated functions, the mechanisms underlying cellular exosomal capture and internalization have received less attention. Thus, understanding the mechanisms of hypoxic exosomes transfer and target cell selection would 


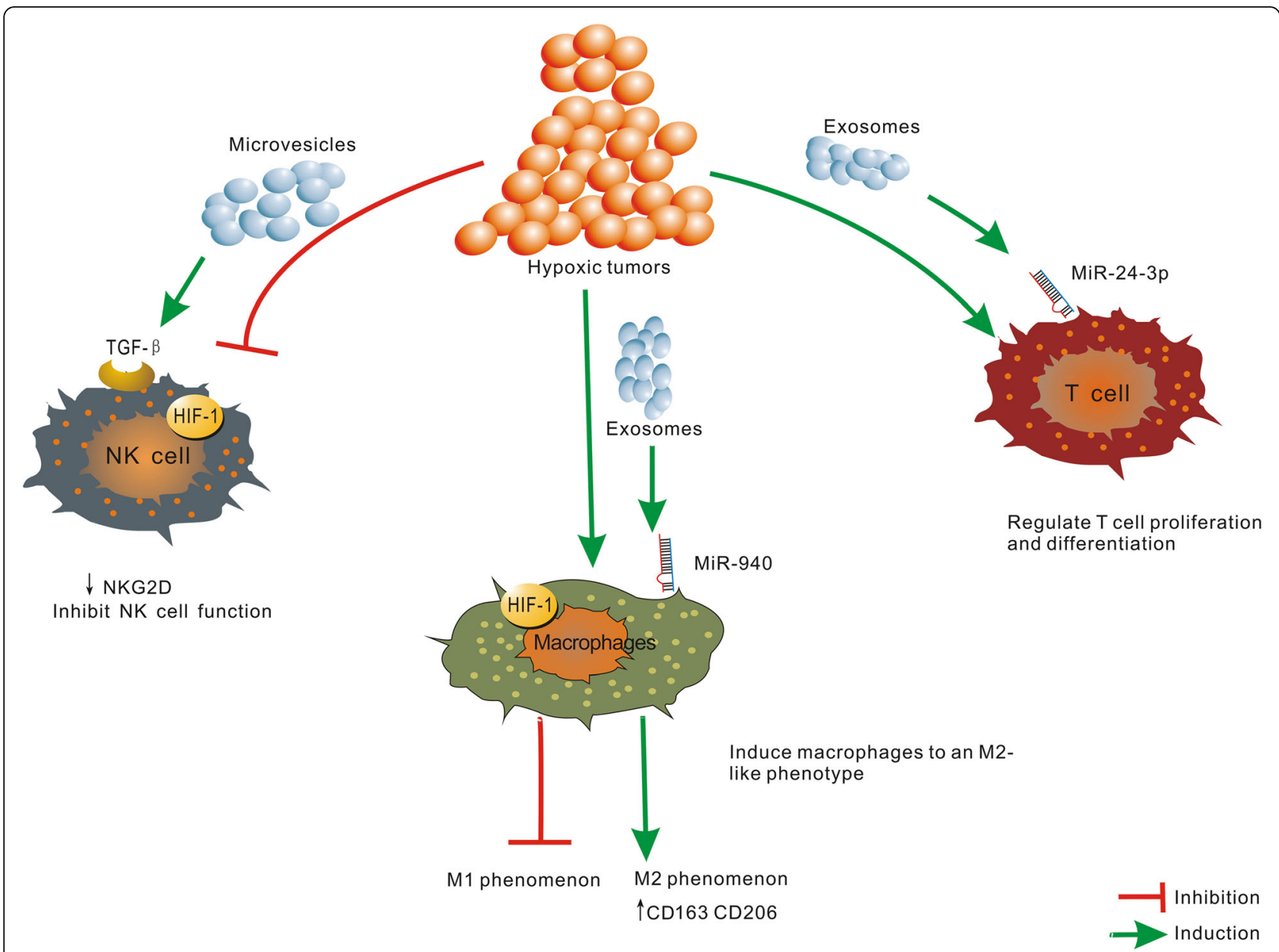

Fig. 2 Exosomes and microvesicles derived from hypoxic tumors are involved in the immune response of tumor microenvironment, including regulation of T-cell proliferation, inhibition of NK cells, activation of macrophages, and promotion of their polarization

improve the prospect of therapeutic targeting of exosomes and their development as therapeutic delivery vehicles. Nevertheless, several challenges are noted for future research on hypoxic exosomes. The direct mechanism of induction extracellular vesicles by HIF and its impact in the modulating processes of exosomes formation and release remains to be determined. Also, the orchestration of these processes during hypoxia necessitate further investigation.

\section{Conclusion}

Hypoxia/HIF regulation on exosome and microvesicles function is now recognized as a new and exciting area in cancer research. The discovery of hypoxia-induced exosomes, especially in the context of long-term hypoxia, has led to an intensive focus on tumor angiogenesis, invasion-metastasis, and immune system in various cancer types. Further investigation is warranted for better understanding the alterations in exosome production and release machinery under hypoxic conditions, which would be helpful in targeting the production of exosomes and prevent metastatic onset in the tumor cells.

\section{Abbreviations}

DC: Dendritic cells; ECM: Extracellular matrix; EGFR: Epidermal growth factor receptor; EMT: Epithelial-to-mesenchymal transition; EVs: Extracellular vesicles; FIH: Factor-inhibiting HIF-1a; HIF: Hypoxia-inducible factor; HR-MM: Hypoxiaresistant multiple myeloma.; IncRNAs: Long non-coding RNAs; miRNAs: MicroRNAs; MSDC: Myeloid-derived suppressor cell; MVBs: Multivesicular bodies; NK: Natural killer cells; NPC: Nasophanyngeal carcinoma; PHD: Prolylhydroxylase; TAM: tumorAssociated macrophages; TDEs: Tumor-derived exosomes; TD-MVs: Tumor-derived microvesicles; TGF-LAP: Transforming growth factor-latency associated protein; TLL: Tumor-infiltrating lymphoid cells; TLR: Toll-like receptor; Tregs: Regulatory T-cells; VHL: von Hippel-Lindau

\section{Funding}

This work was supported by grants from the Natural Science Foundation of Jiangsu Province (Grants No BK20171484), the Project of Invigorating Health Care through Science, Technology, and Education (Jiangsu Provincial Medical Youth Talent QNRC2016856), the National Natural Science Foundation of China (No. 81672896), the Summit of the Six Top Talents Program of Jiangsu Province (2017-WSN-179), Postgraduate Research \& Practice Innovation Program of Jiangsu Province (KYCX18 1483), and the Priority Academic Program Development of Jiangsu Higher Education Institutions (JX10231801). 


\section{Availability of data and materials}

The material supporting the conclusion of this review has been included within the article.

\section{Authors' contributions}

YS, HS, and FY designed the study. CS and FY drafted the manuscript. CS and SM critically revised the manuscript. WL and CW discussed and revised the manuscript. All authors read and approved the final manuscript.

\section{Ethics approval and consent to participate}

Not applicable.

\section{Consent for publication}

Not applicable.

\section{Competing interests}

The authors declare that they have no competing interests.

\section{Publisher's Note}

Springer Nature remains neutral with regard to jurisdictional claims in published maps and institutional affiliations.

\section{Author details}

'Department of Oncology, The Affiliated Sir Run Run Hospital of Nanjing Medical University, Nanjing, China. ${ }^{2}$ Department of Oncology, the First Affiliated Hospital of Nanjing Medical University, 300 Guangzhou Road, Nanjing 210029, People's Republic of China. ${ }^{3}$ Department of Breast Surgery, The First Affiliated Hospital of Nanjing Medical University, Nanjing, China. ${ }^{4}$ Department of Pathology, Nanjing Medical University, Nanjing, China.

Received: 2 May 2018 Accepted: 1 August 2018

Published online: 11 August 2018

\section{References}

1. McKeown SR. Defining normoxia, physoxia and hypoxia in tumours-implications for treatment response. Br J Radiol. 2014:87:20130676.

2. Eales $\mathrm{KL}$, Hollinshead KE, Tennant DA. Hypoxia and metabolic adaptation of cancer cells. Oncogenesis. 2016:5:e190.

3. Ayob AZ, Ramasamy TS. Cancer stem cells as key drivers of tumour progression. J Biomed Sci. 2018;25:20

4. Harris AL. Hypoxia--a key regulatory factor in tumour growth. Nat Rev Cancer. 2002;2:38-47.

5. Brahimi-Horn MC, Chiche J, Pouyssegur J. Hypoxia and cancer. J Mol Med (Berl). 2007;85:1301-7.

6. Gillies RJ, Verduzco D, Gatenby RA. Evolutionary dynamics of carcinogenesis and why targeted therapy does not work. Nat Rev Cancer. 2012;12:487-93.

7. Semenza GL. Hypoxia-inducible factors in physiology and medicine. Cell. 2012;148:399-408.

8. Harada H, Inoue M, Itasaka S, Hirota K, Morinibu A, Shinomiya K, Zeng L, Ou G, Zhu Y, Yoshimura M, et al. Cancer cells that survive radiation therapy acquire HIF-1 activity and translocate towards tumour blood vessels. Nat Commun. 2012;3:783.

9. Semenza GL. The hypoxic tumor microenvironment: a driving force for breast cancer progression. Biochim Biophys Acta. 2016;1863:382-91.

10. Ivan M, Kondo K, Yang H, Kim W, Valiando J, Ohh M, Salic A, Asara JM, Lane WS, Kaelin WJ. HIFalpha targeted for VHL-mediated destruction by proline hydroxylation: implications for O2 sensing. Science. 2001;292:464-8.

11. Chen T, Ren Z, Ye LC, Zhou PH, Xu JM, Shi Q, Yao LQ, Zhong YS. Factor inhibiting HIF1alpha (FIH-1) functions as a tumor suppressor in human colorectal cancer by repressing HIF1alpha pathway. Cancer Biol Ther. 2015; $16: 244-52$.

12. Semenza GL. Targeting HIF-1 for cancer therapy. Nat Rev Cancer. 2003;3:721-32.

13. Lu X, Kang Y. Hypoxia and hypoxia-inducible factors: master regulators of metastasis. Clin Cancer Res. 2010;16:5928-35.

14. Raposo G, Stoorvogel W. Extracellular vesicles: exosomes, microvesicles, and friends. J Cell Biol. 2013;200:373-83.

15. Minciacchi VR, Freeman MR, Di Vizio D. Extracellular vesicles in cancer: exosomes, microvesicles and the emerging role of large oncosomes. Semin Cell Dev Biol. 2015:40:41-51.
16. Kowal J, Arras G, Colombo M, Jouve M, Morath JP, Primdal-Bengtson B, Dingli F, Loew D, Tkach M, Thery C. Proteomic comparison defines novel markers to characterize heterogeneous populations of extracellular vesicle subtypes. Proc Natl Acad Sci U S A. 2016;113:E968-77.

17. Yang F, Ning Z, Ma L, Liu W, Shao C, Shu Y, Shen H. Exosomal miRNAs and miRNA dysregulation in cancer-associated fibroblasts. Mol Cancer. 2017;16:148.

18. Schorey JS, Cheng Y, Singh PP, Smith VL. Exosomes and other extracellular vesicles in host-pathogen interactions. EMBO Rep. 2015;16:24-43.

19. Lopez-Verrilli MA, Court FA. Exosomes: mediators of communication in eukaryotes. Biol Res. 2013;46:5-11.

20. Tkach $\mathrm{M}$, Thery C. Communication by extracellular vesicles: where we are and where we need to go. Cell. 2016;164:1226-32.

21. Syn N, Wang L, Sethi G, Thiery JP, Goh BC. Exosome-mediated metastasis: from epithelial-mesenchymal transition to escape from Immunosurveillance. Trends Pharmacol Sci. 2016:37:606-17.

22. van Niel G, D'Angelo G, Raposo G. Shedding light on the cell biology of extracellular vesicles. Nat Rev Mol Cell Biol. 2018;19(4):213-28.

23. Valadi H, Ekstrom K, Bossios A, Sjostrand M, Lee JJ, Lotvall JO. Exosome mediated transfer of mRNAs and microRNAs is a novel mechanism of genetic exchange between cells. Nat Cell Biol. 2007;9:654-9.

24. Hannafon BN, Ding WQ. Intercellular communication by exosome-derived microRNAs in cancer. Int J Mol Sci. 2013;14:14240-69.

25. Milane L, Singh A, Mattheolabakis G, Suresh M, Amiji MM. Exosome mediated communication within the tumor microenvironment. J Control Release. 2015;219:278-94.

26. Sun T, Kalionis B, Lv G, Xia S, Gao W. Role of Exosomal noncoding RNAs in lung carcinogenesis. Biomed Res Int. 2015;2015:125807.

27. Li Q, Shao Y, Zhang X, Zheng T, Miao M, Qin L, Wang B, Ye G, Xiao B, Guo J. Plasma long noncoding RNA protected by exosomes as a potential stable biomarker for gastric cancer. Tumour Biol. 2015;36:2007-12.

28. Gezer U, Ozgur E, Cetinkaya M, Isin M, Dalay N. Long non-coding RNAs with low expression levels in cells are enriched in secreted exosomes. Cell Biol Int. 2014;38:1076-9.

29. Zhang W, Zhou X, Yao Q, Liu Y, Zhang H, Dong Z. HIF-1-mediated production of exosomes during hypoxia is protective in renal tubular cells. Am J Physiol Renal Physiol. 2017;313:F906-13.

30. Park JE, Tan HS, Datta A, Lai RC, Zhang H, Meng W, Lim SK, Sze SK. Hypoxic tumor cell modulates its microenvironment to enhance angiogenic and metastatic potential by secretion of proteins and exosomes. Mol Cell Proteomics. 2010;9:1085-99.

31. Wang T, Gilkes DM, Takano N, Xiang L, Luo W, Bishop CJ, Chaturvedi P, Green JJ, Semenza GL. Hypoxia-inducible factors and RAB22A mediate formation of microvesicles that stimulate breast cancer invasion and metastasis. Proc Natl Acad Sci U S A. 2014;111:E3234-42.

32. Huber MA, Kraut N, Beug H. Molecular requirements for epithelial-mesenchymal transition during tumor progression. Curr Opin Cell Biol. 2005;17:548-58.

33. Ostrowski M, Carmo NB, Krumeich S, Fanget I, Raposo G, Savina A, Moita CF, Schauer K, Hume AN, Freitas RP, et al. Rab27a and Rab27b control different steps of the exosome secretion pathway. Nat Cell Biol. 2010;12:19-30. 1-13

34. Bobrie A, Krumeich S, Reyal F, Recchi C, Moita LF, Seabra MC, Ostrowski M, Thery C. Rab27a supports exosome-dependent and -independent mechanisms that modify the tumor microenvironment and can promote tumor progression. Cancer Res. 2012;72:4920-30.

35. Kore RA, Edmondson JL, Jenkins SV, Jamshidi-Parsian A, Dings R, Reyna NS, Griffin RJ. Hypoxia-derived exosomes induce putative altered pathways in biosynthesis and ion regulatory channels in glioblastoma cells. Biochem Biophys Rep. 2018;14:104-13.

36. King HW, Michael MZ, Gleadle JM. Hypoxic enhancement of exosome release by breast cancer cells. BMC Cancer. 2012;12:421.

37. Umezu T, Tadokoro H, Azuma K, Yoshizawa S, Ohyashiki K, Ohyashiki JH. Exosomal miR-135b shed from hypoxic multiple myeloma cells enhances angiogenesis by targeting factor-inhibiting HIF-1. Blood. 2014;124:3748-57.

38. Hanahan D, Weinberg RA. Hallmarks of cancer: the next generation. Cell. 2011;144:646-74.

39. Borges FT, Melo SA, Ozdemir BC, Kato N, Revuelta I, Miller CA, Gattone VN, LeBleu VS, Kalluri R. TGF-beta1-containing exosomes from injured epithelial cells activate fibroblasts to initiate tissue regenerative responses and fibrosis. J Am Soc Nephrol. 2013;24:385-92.

40. Walsh TG, Metharom P. Berndt MC The functional role of platelets in the regulation of angiogenesis. Platelets. 2015;26:199-211. 
41. Mousa L, Salem ME, Mikhail S. Biomarkers of angiogenesis in colorectal Cancer. Biomark Cancer. 2015;7:13-9.

42. Olsson AK, Dimberg A, Kreuger J, Claesson-Welsh L. VEGF receptor signalling in control of vascular function. Nat Rev Mol Cell Biol. 2006;7:359-71.

43. Zhao Y, Adjei AA. Targeting angiogenesis in Cancer therapy: moving beyond vascular endothelial growth factor. Oncologist. 2015;20:660-73.

44. Hsu YL, Hung JY, Chang WA, Lin YS, Pan YC, Tsai PH, Wu CY, Kuo PL. Hypoxic lung cancer-secreted exosomal miR-23a increased angiogenesis and vascular permeability by targeting prolyl hydroxylase and tight junction protein ZO-1. Oncogene. 2017;36:4929-42.

45. Tadokoro H, Umezu T, Ohyashiki K, Hirano T, Ohyashiki JH. Exosomes derived from hypoxic leukemia cells enhance tube formation in endothelial cells. J Biol Chem. 2013;288:34343-51.

46. Mao G, Liu Y, Fang X, Liu Y, Fang L, Lin L, Liu X, Wang N. Tumor-derived microRNA-494 promotes angiogenesis in non-small cell lung cancer. Angiogenesis. 2015;18:373-82.

47. Tan EJ, Olsson AK, Moustakas A. Reprogramming during epithelial to mesenchymal transition under the control of TGFbeta. Cell Adhes Migr. 2015;9:233-46.

48. Peng Z, Wang CX, Fang EH, Wang GB, Tong Q. Role of epithelial-mesenchymal transition in gastric cancer initiation and progression. World J Gastroenterol. 2014;20:5403-10

49. Panebianco C, Saracino C, Pazienza V. Epithelial-mesenchymal transition: molecular pathways of hepatitis viruses-induced hepatocellular carcinoma progression. Tumour Biol. 2014;35:7307-15.

50. Baranwal S, Alahari SK. Molecular mechanisms controlling E-cadherin expression in breast cancer. Biochem Biophys Res Commun. 2009;384:6-11.

51. Inge $L$, Rajasekaran $S A$, Wolle $D$, Barwe $S P$, Ryazantsev $S$, Ewing CM, Isaacs WB, Rajasekaran AK. alpha-catenin overrides Src-dependent activation of beta-catenin oncogenic signaling. Mol Cancer Ther. 2008;7:1386-97.

52. Ebnet K. Organization of multiprotein complexes at cell-cell junctions. Histochem Cell Biol. 2008;130:1-20.

53. Onder TT, Gupta PB, Mani SA, Yang J, Lander ES, Weinberg RA. Loss of E-cadherin promotes metastasis via multiple downstream transcriptional pathways. Cancer Res. 2008;68:3645-54.

54. Ramteke A, Ting H, Agarwal C, Mateen S, Somasagara R, Hussain A, Graner M, Frederick B, Agarwal R, Deep G. Exosomes secreted under hypoxia enhance invasiveness and stemness of prostate cancer cells by targeting adherens junction molecules. Mol Carcinog. 2015;54:554-65.

55. Xue M, Chen W, Xiang A, Wang R, Chen H, Pan J, Pang H, An H, Wang X, Hou $\mathrm{H}, \mathrm{Li}$ X. Hypoxic exosomes facilitate bladder tumor growth and development through transferring long non-coding RNA-UCA1. Mol Cancer. 2017;16:143.

56. Li L, Li C, Wang S, Wang Z, Jiang J, Wang W, Li X, Chen J, Liu K, Li C, Zhu G. Exosomes derived from hypoxic oral squamous cell carcinoma cells deliver miR-21 to normoxic cells to elicit a Prometastatic phenotype. Cancer Res. 2016:76:1770-80.

57. Costa-Silva B, Aiello NM, Ocean AJ, Singh S, Zhang H, Thakur BK, Becker A, Hoshino A, Mark MT, Molina $\mathrm{H}$, et al. Pancreatic cancer exosomes initiate pre-metastatic niche formation in the liver. Nat Cell Biol. 2015;17:816-26.

58. Sceneay J, Parker BS, Smyth MJ, Moller A. Hypoxia-driven immunosuppression contributes to the pre-metastatic niche. Oncoimmunology. 2013;2:e22355.

59. Sceneay J, Smyth MJ, Moller A. The pre-metastatic niche: finding common ground. Cancer Metastasis Rev. 2013;32:449-64.

60. Filipazzi P, Burdek M, Villa A, Rivoltini L, Huber V. Recent advances on the role of tumor exosomes in immunosuppression and disease progression. Semin Cancer Biol. 2012;22:342-9.

61. Poutsiaka DD, Schroder EW, Taylor DD, Levy EM, Black PH. Membrane vesicles shed by murine melanoma cells selectively inhibit the expression of la antigen by macrophages. J Immunol. 1985;134:138-44.

62. Andreola G, Rivoltini L, Castelli C, Huber V, Perego P, Deho P, Squarcina P. Accornero $P$, Lozupone F, Lugini L, et al. Induction of lymphocyte apoptosis by tumor cell secretion of FasL-bearing microvesicles. J Exp Med. 2002;195:1303-16,

63. Liu C, Yu S, Zinn K, Wang J, Zhang L, Jia Y, Kappes JC, Barnes S, Kimberly RP, Grizzle WE, Zhang HG. Murine mammary carcinoma exosomes promote tumor growth by suppression of NK cell function. J Immunol. 2006;176:1375-85.

64. Valenti R, Huber V, Filipazzi P, Pilla L, Sovena G, Villa A, Corbelli A, Fais S, Parmiani $G$, Rivoltini L. Human tumor-released microvesicles promote the differentiation of myeloid cells with transforming growth factor-beta-mediated suppressive activity on T lymphocytes. Cancer Res. 2006;66:9290-8.
65. Wen SW, Sceneay J, Lima LG, Wong CS, Becker M, Krumeich S, Lobb RJ, Castillo V, Wong KN, Ellis S, et al. The biodistribution and immune suppressive effects of breast Cancer-derived exosomes. Cancer Res. 2016;76:6816-27.

66. Fabbri M, Paone A, Calore F, Galli R, Gaudio E, Santhanam R, Lovat F, Fadda P, Mao C, Nuovo GJ, et al. MicroRNAs bind to toll-like receptors to induce prometastatic inflammatory response. Proc Natl Acad Sci U S A. 2012;109:E2110-6

67. Szczepanski MJ, Szajnik M, Welsh A, Whiteside TL, Boyiadzis M. Blast-derived microvesicles in sera from patients with acute myeloid leukemia suppress natural killer cell function via membrane-associated transforming growth factor-beta1. Haematologica. 2011;96:1302-9.

68. Figueiro F, Muller L, Funk S, Jackson EK, Battastini AM, Whiteside TL. Phenotypic and functional characteristics of CD39(high) human regulatory B cells (Breg). Oncoimmunology. 2016;5:e1082703.

69. Liu Y, Xiang X, Zhuang X, Zhang S, Liu C, Cheng Z, Michalek S, Grizzle W, Zhang HG. Contribution of MyD88 to the tumor exosome-mediated induction of myeloid derived suppressor cells. Am J Pathol. 2010;176:2490-9.

70. Chen X, Ying X, Wang X, Wu X, Zhu Q, Wang X. Exosomes derived from hypoxic epithelial ovarian cancer deliver microRNA-940 to induce macrophage M2 polarization. Oncol Rep. 2017;38:522-8.

71. Ye SB, Zhang H, Cai TT, Liu YN, Ni JJ, He J, Peng JY, Chen QY, Mo HY, Juncui, et al. Exosomal miR-24-3p impedes T-cell function by targeting FGF11 and serves as a potential prognostic biomarker for nasopharyngeal carcinoma. J Pathol. 2016;240:329-40.

72. Jung KO, Youn H, Lee CH, Kang KW, Chung JK. Visualization of exosomemediated miR-210 transfer from hypoxic tumor cells. Oncotarget. 2017:8:9899-910

73. Takahashi K, Yan IK, Haga H, Patel T. Modulation of hypoxia-signaling pathways by extracellular linc-RoR. J Cell Sci. 2014;127:1585-94.

74. Horie K, Kawakami K, Fujita Y, Sugaya M, Kameyama K, Mizutani K, Deguchi T, Ito M. Exosomes expressing carbonic anhydrase 9 promote angiogenesis. Biochem Biophys Res Commun. 2017;492:356-61.

75. Svensson KJ, Kucharzewska P, Christianson HC, Skold S, Lofstedt T, Johansson MC, Morgelin M, Bengzon J, Ruf W, Belting M. Hypoxia triggers a proangiogenic pathway involving cancer cell microvesicles and PAR-2mediated heparin-binding EGF signaling in endothelial cells. Proc Natl Acad Sci U S A. 2011:108:13147-52.

76. Huang Z, Feng Y. Exosomes derived from hypoxic colorectal Cancer cells promote angiogenesis through Wnt4-induced beta-catenin signaling in endothelial cells. Oncol Res. 2017;25:651-61.

77. Shan Y, You B, Shi S, Shi W, Zhang Z, Zhang Q, Gu M, Chen J, Bao L, Liu D, You Y. Hypoxia-induced matrix Metalloproteinase-13 expression in exosomes from nasopharyngeal carcinoma enhances metastases. Cell Death Dis. 2018;9:382.

78. Aga M, Bentz GL, Raffa S, Torrisi MR, Kondo S, Wakisaka N, Yoshizaki T, Pagano JS, Shackelford J. Exosomal HIF1alpha supports invasive potential of nasopharyngeal carcinoma-associated LMP1-positive exosomes. Oncogene. 2014;33:4613-22.

79. Berchem G, Noman MZ, Bosseler M, Paggetti J, Baconnais S, Le Cam E, Nanbakhsh A, Moussay E, Mami-Chouaib F, Janji B, Chouaib S. Hypoxic tumor-derived microvesicles negatively regulate NK cell function by a mechanism involving TGF-beta and miR23a transfer. Oncoimmunology. 2016:5:e1062968.

\section{Ready to submit your research? Choose BMC and benefit from:}

- fast, convenient online submission

- thorough peer review by experienced researchers in your field

- rapid publication on acceptance

- support for research data, including large and complex data types

- gold Open Access which fosters wider collaboration and increased citations

- maximum visibility for your research: over $100 \mathrm{M}$ website views per year

At $\mathrm{BMC}$, research is always in progress.

Learn more biomedcentral.com/submission 